\title{
Facile Preparation, Characterization of Flexible Organic Solar Cells Using P3HT-MWCNTS Composite Photoactive Layer
}

\author{
Tran Si Trong Khanh, Nguyen Phuong Hoai Nam, Nguyen Nang Dinh \\ Advanced Research Group of Nano-Semiconducting Materials and Devices (ARGD), University of Engineering and Technology, \\ VNU in Hanoi, Hanoi, Vietnam \\ Email:dinh158@gmail.com,dinhnn@vnu.edu.vn
}

How to cite this paper: Khanh, T.S.T., Nam, N.P.H. and Dinh, N.N. (2020) Facile Preparation, Characterization of Flexible Organic Solar Cells Using P3HT-MWCNTS Composite Photoactive Layer. Journal of Materials Science and Chemical Engineering, 8, 1-10.

https://doi.org/10.4236/msce.2020.810001

Received: August 11, 2020

Accepted: September 27, 2020

Published: September 30, 2020

Copyright $\odot 2020$ by author(s) and Scientific Research Publishing Inc. This work is licensed under the Creative Commons Attribution International License (CC BY 4.0).

http://creativecommons.org/licenses/by/4.0/

\begin{abstract}
Multiwalled carbon nanotubes (MWCNTs) mixed in poly(3-hexylthiophene) ( $\mathrm{P} 3 \mathrm{HT})$ were used as a photoactive layer for organic solar cells (OSC). The flexible OSCs of a structure of PET/rGO-P3HT/P3CT/PCBM/LiF-Al were prepared by spincoating. The UV-Vis absorption spectra of the photoactive films and current-voltage characteristics of the OSCs showed the advantage of the composite devices above the pristine-polymeric ones. Under illumination of light with a $100 \mathrm{~mW} / \mathrm{cm}^{2}$-powerdensity, the photoelectrical conversion efficiency (PCE) of the OSCs with $3.0 \mathrm{wt} \%$ MWNCTs embedded in the photoactive layer possess a value as large as $2.35 \%$. The obtained results suggest further useful applications of the flexible large-area solar cells.
\end{abstract}

\section{Keywords}

P3HT-MWCNTs, Composite Photovoltage, UV-Vis Absorption, Photoluminescence (PL) Quenching, J-V Characteristics, Photoelectrical Conversion Efficiency (PCE)

\section{Introduction}

Recently, organic electronics based on conducting polymers (CPs) has been increasingly interesting because CPs have many advantages, such as they can be easily prepared in thin films, their bandgap (the gap between the Lowest Unoccupied Molecule Orbital (LUMO) and the highest occupied Molecule Orbital (HOMO) can be adjusted by chemical methods. CPs have been applied in organic light-emitting diodes (OLEDs), Organic Gas Sensors (OGS), Organic Solar Cells (OSC), etc. [1] [2] [3] [4] [5]. Among the CPs, poly(3-hexylthiophene) 
(P3HT) is mostly used for OGSs and OSCs because P3HT possesses a rather narrow energy bandgap (1.93 - $1.95 \mathrm{eV}$ [6]) enabling it to absorb a large solar energy spectrum. P3HT is served as an electron donor material [7], while $[6,6]$-phenyl $\mathrm{C}_{61}$-butyric acid methyl ester (PCBM) is used as an electron acceptor one [8]. Comparing to c-Si cells, the production for both the materials and devices of OSCs requires less expensive equipment: instead of the crystal growth, the liquid-phase epitaxy and the ion implantation, simple techniques like spin coating or sol-gel dip coating can be used for making thin films of the P3HT-based photoactive layer. However, the photoelectrical conversion efficiency (PCE) of OSCs is much lower than that of c-Si cells. This is mainly due to the strong decay of the excitons or electron-hole pairs (EHPs), that is generated in the donors/acceptors junctions owing to the solar radiation. A way to eliminate the probability of the EHPs recombination is embedding inorganic particles into the photoactive layer to form a nanocomposite material, resulting in so-called charge separation. Thomas et al. [9] and Liu et al. [10] have shown that the PCE can be enhanced by the use of composite photovoltaic materials. We have also demonstrated that using a nanocomposite $\mathrm{P} 3 \mathrm{HT}+\mathrm{nc}^{-}-\mathrm{TiO}_{2}$ as the photoactive layer, the PCE of OSCs has maintained value as large as $1.2 \%$ at a temperature of $130^{\circ} \mathrm{C}$ due to the enhancement of the thermal endurance [11]. It is well-known that carbon nanotubes (CNTs) possess remarkable properties for applications in molecular electronics, energy storage, sensors, new composites for solar cells, etc. Cai et al. [12] have used a composite of P3HT and bamboo-structured CNTs for the efficient hole transport layer (HTL) in $\mathrm{CH}_{3} \mathrm{NH}_{3} \mathrm{PbI}_{3} \mathrm{I}$-based perovskite solar cells. The PCE of the cells increased in more two times (namely from $3.6 \%$ for pristine $\mathrm{P} 3 \mathrm{HT}$ to $8.3 \%$ for $\mathrm{P} 3 \mathrm{HT}+$ CNT). Mombrú et al. [13] have used multiwalled carbon nanotube (MWCNT) mixed with poly(3,4-ethylene dioxythiophene): poly(styrene sulfonate) composites (PEDOT: PSS-MWCNTs) for electrodes in solar cell applications. The authors showed that the large out-of-plane conductivity of the devices was much improved due to the addition of MWCNTs in the PEDOT: PSS films. Kuila et al. [14] pointed out that both the HOMO and LUMO energy levels of the $\mathrm{P} 3 \mathrm{HT}+\mathrm{CNTs}$ material served as the photoactive layer were lowered comparing with those of pristine P3HT. Jun et al. [15] fabricated OSCs using reduced graphene oxide (rGO)/P3HT: PCBM as a photoactive layer. The authors denoted that the PCE of the device can be much enhanced by both the charge selectivity and effective charge transport of $\mathrm{rGO}$ in $\mathrm{P} 3 \mathrm{HT}$ polymer. The largest PCE was found to be of $4.5 \%$ for the OSCs using rGO doped with $5.0 \mathrm{wt} \%$ of nitrogen. However, for producing the devices, ITO-coated glass served as the transparent conducting electrode (TCE) and PEDOT-PSS - as the HTL were used. Recently [16], we prepared rGO-P3HT films with electrical and optical properties suitable to TCEs using for optoelectrical devices, especially OSCs.

In this work, we present a facile method for producing MWCNTs-P3HT: PCBM-based OSCs without ITO-coated glass substrate and PEDOT-PSS layer. The absorption and photoluminescence properties of the composite photoactive 
layer as well as the photoelectrical conversion performances of the devices were also presented.

\section{Experiment and Method}

The photoactive films were prepared by spin coating method that was described elsewhere [11]. To compare the photoactive properties of a pristine $\mathrm{P} 3 \mathrm{HT}$ and a $\mathrm{P} 3 \mathrm{HT}+\mathrm{MWCNTs}$ composite (abbreviated to $\mathrm{P} 3 \mathrm{CT}$ ) as well as the performance parameters of the devices, pristine $\mathrm{P} 3 \mathrm{HT}$ and $\mathrm{P} 3 \mathrm{CT}$ films were prepared with the same technological conditions. The MWCNTs of $30-50 \mathrm{~nm}$ in diameter and rGO of $99.9 \%$ purity were supplied by the Institute of Materials Science, Vietnamese Academy of Science and Technology (VAST). rGO-P3HT-coated PET (transparent conducting substrate), further called GPP, was used as an anode. These GPP flexible substrates (with a sheet resistance of ca. $50 \Omega$ and a transmittance of ca. $85 \%$ ) were produced following the procedure as described in [16]. The aluminum (Al) coating was used for a cathode and also for a reflecting mirror. P3HT solutions were prepared by dissolving $8 \mathrm{mg}$ of P3HT powders in 1 $\mathrm{ml}$ of chlorobenzene. To prepare P3HT-MWCNTs composites, MWCNTs were mixed in P3HT solution by a MWCNTs/polymer weight ratio of 0.015 to 0.030 and 0.050 (namely 1.0, 3.0 and $5.0 \mathrm{wt} \%$ ). Further, the devices with the additive of 1.5, 3.0 and $5.0 \mathrm{wt} \%$ MWCNTs are abbreviated to P3CT-15, P3CT-30 and P3CT-50, respectively. Uniform distribution and a complete dispersion of MWCNTs in P3HT were obtained by magnetically stirring the solutions for 12 h. Next step, pristine P3HT and P3CT solutions were spin-coated onto the GPP substrates according to conditions: a delay time of $120 \mathrm{~s}$, a rest time of $30 \mathrm{~s}$, a spin speed of $1500 \mathrm{rpm}$, and an acceleration of $500 \mathrm{rpm}$, and finally a drying time of $2 \mathrm{~min}$. All the sample then were annealed in an exceed nitrogen pressure (namely 1.05 at) at a temperature ranging from $120^{\circ} \mathrm{C}$ to $180^{\circ} \mathrm{C}$ for $8 \mathrm{~h}$. The thickness of P3HT and P3CT layers deposited in our experiments has a value of $100 \mathrm{~nm}$. For photoluminescence and UV-Vis measurements, P3HT and P3CT films of the same thickness were coated onto corning-247 glass substrates. A 50 nm-thick fullerene derivative 1-(3-methoxycarbonyl) propyl-1-phenyl[6,6]C61 (PCBM) served as the acceptor layer was then deposited onto both photoactive layers (namely P3HT and P3CT). Finally, $\mathrm{LiF} / \mathrm{Al}$ electrodes (served as the shallow contact [11]) was successively evaporated (30 $\mathrm{nm}$ for $\mathrm{LiF}$ and $70 \mathrm{~nm}$ for $\mathrm{Al}$ ) onto PCBM layer, using a mask with windows of $5.0 \mathrm{~mm} \times 5.0 \mathrm{~mm}$ in size (the active area of the cells was of $0.25 \mathrm{~cm}^{2}$ ). Thus, two types of OSCs with a structure of GPP/P3HT/PCBM/LiF-Al and GPP/P3CT/PCBM/LiF-Al were prepared. The structure of a typical of the composite device is presented in Figure 1. The thickness of all the functional layers (anode, photoactive film, PCBM and cathode) is of $\sim 350 \mathrm{~nm}$ that is negligible comparing to the PET substrate (i.e. 350 $\mathrm{nm}$ compared to $350 \mu \mathrm{m}$ ). Thus the device thickness can be seen as the thickness of the PET substrate.

The surface morphology pictures MWCNTs and composite samples were made by using a High-Resolution Transmittance (HR-TEM) and Field-Emission 


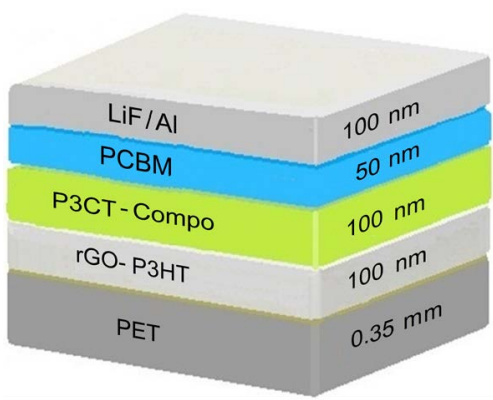

Figure 1. Schematic drawing of a PET/rGO-P3HT/P3CT/PCBM/LiF/Al device made from the functional layers with shown thicknesses.

Scanning Electron Microscopy (FE-SEM), respectively ("Hitachi" Ltd.). The photoluminescence (PL) spectra and the ultraviolet-visible absorption spectra of the samples were carried out on a HORIBA "FL3-2" spectrophotometer and a JASCO UV-VIS-Nir "V570", respectively. The photocurrent density-voltage $(J-V)$ characteristics of the two types of the OCSs were measured on the current-voltage unit under radiation of $100 \mathrm{~mW} / \mathrm{cm}^{2}$ (or AM1.5) taken from "Sol $1 \mathrm{~A}$ " Newport solar simulator source.

\section{Results and Discussion}

\subsection{Morphology, Photoluminescence and UV-Vis Analysis}

Figure 2 shows the surface morphology of MWCNTs and P3CT film with a percentage of $3.0 \mathrm{wt} \%$ MWCNTs. This figure demonstrates that the MWCNTs were well embedded in the polymer. The heat treatment at the above-mentioned temperatures not much affected on the morphology of the films, thus negligible differences in the morphology of the sample were observed when annealed at $\mathrm{T}_{\mathrm{a}}$ of $120^{\circ} \mathrm{C}$ to $160^{\circ} \mathrm{C}$ and $180^{\circ} \mathrm{C}$. From preliminary measurements of the current-voltage (I-V) characteristics, it was found that the samples annealed at $160^{\circ} \mathrm{C}$ exhibited the best $\mathrm{I}-\mathrm{V}$ performance. Thus, for further investigations all the samples concerned were annealed at $160^{\circ} \mathrm{C}$ for $8 \mathrm{~h}$.

Prior to choose an appropriate composition in the composites used for photoactive layers, we investigated photoluminescent properties of both the pristine polymer and composite films, namely $\mathrm{P} 3 \mathrm{HT}$ and $\mathrm{P} 3 \mathrm{CT}$ mixed with different concentrations of MWCNTs. The aim of the investigation is searching for the composite which has the strongest photoluminescence quenching effect which indicates the largest possibility of the charge separation in the photoactive layer. The PL spectra of the samples measured at an excitation wavelength of $470 \mathrm{~nm}$ are presented in Figure 3.

Strong luminous quenching of the samples was observed at wavelengths around $580 \mathrm{~nm}$ (corresponding to $\pi-\pi^{*}$ bonding in P3HT). The effect of the luminous quenching proves the electrons transport from the LUMO band of P3HT to the LUMO band of PCBM, and holes-from HOMO band of P3HT to the HOMO of MWCNT through the P3HT/PCBM and P3HT/MWCNT heterojunctions in the nanocomposite, respectively. The quenching efficiency can be 


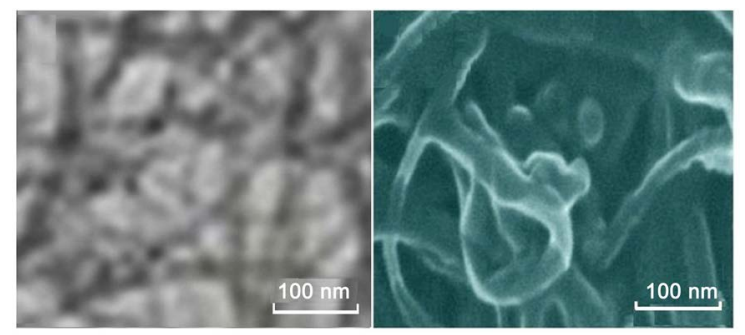

(a)

(b)

Figure 2. (a) TEM image MWCNTs and (b) FE-SEM micrograph a composite film with the MWCNTs/P3HT ratio is $3.0 \mathrm{wt} \%$ annealed at $160^{\circ} \mathrm{C}$, for $8 \mathrm{~h}$.

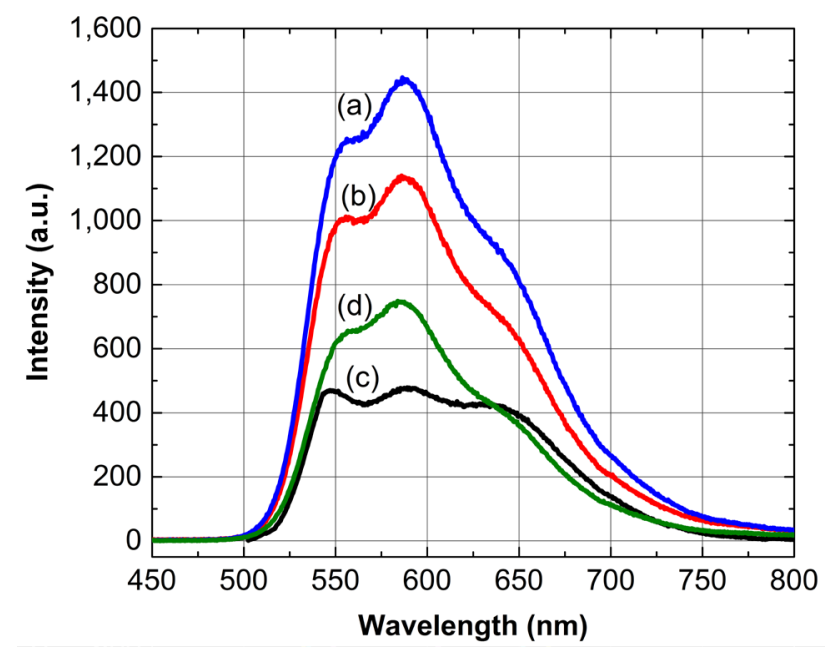

Figure 3. PL spectra of a pristine P3HT (a) and composite films with the MWCNTs additive of $1.5 \mathrm{wt} \%$ (b), $3.0 \mathrm{wt} \%$ (c) and $5.0 \mathrm{wt} \%$ (d). The excitation wavelength $\lambda=470 \mathrm{~nm}$.

qualitatively estimated by a relative quenching coefficient $(\chi, \%)$ that is calculated by following equation.

$$
\chi=\frac{I_{p}-I_{c}}{I_{p}} \times 100 \%
$$

where $I_{p}$ and $I_{c}$ are the intensities of the PL peak of polymers and composites, respectively.

Taking values of $I_{p}$ and $I_{c}$ from Figure 3 and applying Equation (1), $\chi$ was found to be of $18 \%, 72 \%$ and $47 \%$, respectively for $1.5,3.0$ and $5.0 \mathrm{wt} \%$ MWCNTs embedded in P3CT films. Thipperudrappa et al. [17] showed that the fractional intensity $I_{p} / I_{c}$ is given by the product of both static and dynamic quenching. The authors also denoted that instantaneous or static quenching occurs if the quencher substances are very near to, or in contact with fluorescent molecules at the moment of its excitation. In other words, the electron-hole pairs generated at the heterojunctions (i.e. $\mathrm{P} 3 \mathrm{HT} / \mathrm{MWCNT}$ interfaces) are not recombined; they are separated from each other, resulting in the luminous quenching of polymeric composite thin films. This is a specific property that is desired for designing an OSC with the large PCE. The fact that the quenching is closely involved to the charge separation proves that the luminous quenching 
can be considered as a useful factor for choosing a combination of conducting polymers and inorganic nanoparticles used for devices fabrication. Thus, in our experiments, the $\mathrm{P} 3 \mathrm{HT}$ with an additive of $3.0 \mathrm{wt} \%$ MWCNTs (i.e. P3CT-30 sample) possessing the largest $\chi(72 \%)$ can be used for making photoactive layer in P3HT-MWCNT based solar cells.

Next, the absorption spectra of both P3HT/glass the P3HT-30/glass samples wre characterized. To eliminate the glass absorption, the absorption spectra of both the pristine P3HT and P3CT-30 films were measured under a baseline regime. The measured results are presented in Figure 4(a), showing a clear difference in absorption related to $\pi-\pi^{*}$ bonding for two samples, at the wavelength around $550 \mathrm{~nm}$, in particular. At this wavelength, comparing to the $\mathrm{P} 3 \mathrm{HT}$, the composite film much stronger absorbed, namely the absorption coefficient of the composite sample is nearly $30 \%$ larger than the one of the pristine P3HT. The $\pi-\pi^{*}$ absorption peak of the pure P3HT and P3CT-30 composite film is located at $555 \mathrm{~nm}$ and $545 \mathrm{~nm}$, respectively. This blue-shift was attributed to the more disordered chain conformation in P3HT embedded with MWCNTs [14]. The authors pointed out that the disordered conformation in the $\mathrm{P} 3 \mathrm{HT}$ chain results in a more amorphous structure in the composite film.

To determine the gap between HOMO and LOMO of a conducting polymer that is similar to the energy bandgap $\left(E_{g}\right)$ of the inorganic semiconductors, one can use data obtained by UV-Vis spectra measurements. It is known that the relationship between the bandgap and absorption coefficient of the semiconducting materials are expressed by the following formula [18]:

$$
\alpha h v=A\left(h v-E_{g}\right)^{n}
$$

where $h$ is Planck's constant, $v$ is the frequency of the incident UV-Vis radiation, $A$ is a constant and $n$ is $1 / 2$ for direct band semiconductors and 2 for indirect bandgap semiconductors.

For both the P3HT and P3CT samples, $n=2$ is the best fit. The $h v$-dependences of $(\alpha h v)^{1 / 2}$ of the samples are plotted in Figure 4(b). Extending the linear $h v$-dependence of $(\alpha h v)^{1 / 2}$ to cross the abscissa, the value of $E_{g}$ of the P3HT and P3CT-30 films was found to be $1.95 \mathrm{eV}$ and $1.93 \mathrm{eV}$, respectively. The first value

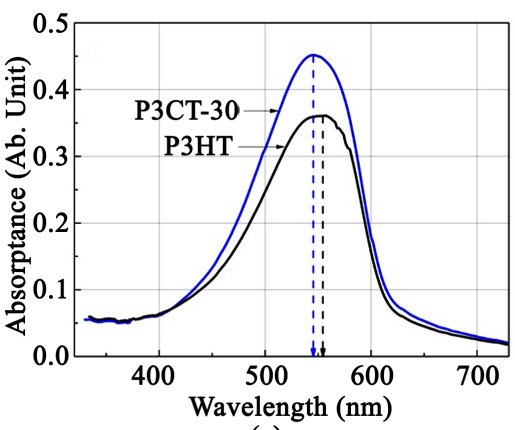

(a)

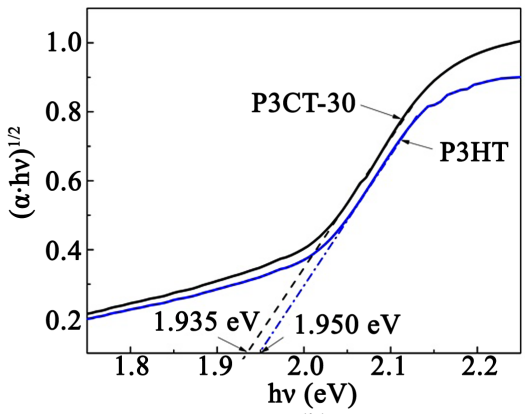

(b)

Figure 4. UV-Vis spectra of a pristine P3HT and a P3CT-30 films (a) and the plots of $(\alpha h v)^{2}$ vs. photon energy $(h v)$ for their $\mathrm{E}_{\mathrm{g}}$ determination (b). 
is rightly $E_{g}$ value as reported by Ren et al. [6] when P3HT was prepared for the hybrid solar cells. The smaller value in the bandgap of the composite film (1.93 $\mathrm{eV}$ ) is explained by the lowering LUMO energy level of the polymer due to the presence of the MWCNTs [14]. The absorption of the P3CT films in the wavelengths range from $400 \mathrm{~nm}$ to $600 \mathrm{~nm}$ is much larger comparing to the pristine $\mathrm{P} 3 \mathrm{HT}$ film. This fact proves the advantage in the solar energy absorption of the composite-based photoactive layer in comparison with the pristine polymer.

\subsection{Characterization of Device Performance}

Performance parameters of a PV device such as open-circuit voltage $\left(V_{o c}\right)$, short-circuit current density $\left(J_{s c}\right)$ and the fill factor $(\mathrm{FF})$ were determined from experimental data obtained from voltage dependence of the current density, namely J-V characteristics. Figure 5 shows the J-V curves of the two devices, pristine P3HT and P3CT-30, under illumination with a power density of 100 $\mathrm{mW} / \mathrm{cm}^{2}$.

The FF of the devices is calculated from the following formula:

$$
\mathrm{FF}=\frac{(J \times V)_{\max }}{J_{s c} \times V_{o c}}
$$

where $(J \times V)_{\max }$ is the largest value from all the $J \times V$. The photoelectrical conversion efficiency, PCE, denoted as $\eta$, can be determined by:

$$
\eta=\frac{\mathrm{FF} \times J_{s c} \times V_{o c}}{P_{i n}}
$$

where $P_{i n}$ is the density of the illuminating power, in $\mathrm{mW} / \mathrm{cm}^{2}$. In our experiments $P_{\text {in }}=100 \mathrm{~mW} / \mathrm{cm}^{2}$ ). All the values of the performance parameters determined from J-V curves and Equations (3) and (4) are listed in Table 1.

Comparing to the pristine-polymer device, the $V_{o c}$ of the P3CT-30 is negligibly smaller $(0.87 \mathrm{~V}$ compared to $0.89 \mathrm{~V})$, but the $J_{s c}$ is much larger $\left(5.05 \mathrm{~mA} / \mathrm{cm}^{2}\right.$ to $4.1 \mathrm{~mA} / \mathrm{cm}^{2}$ ). The fact that the $\mathrm{FF}$ of the $\mathrm{P} 3 \mathrm{CT}$ is larger than that of $\mathrm{P} 3 \mathrm{HT}$ based OSC proves that the intrinsic resistance of the composite device is smaller than the one of the pristine-polymer device. This is due to: 1) the presence of rGO in the TCE and 2) MWCNTs in P3HT polymer. Using a scheme of the energy levels demonstrated in Figure 6 that is built up from the data of the energy bandgap structure of the single components in the photovoltaic cell (shown f.i. in [14] and [19]), one can explain the increase in the $J_{s c}$ of the P3CT-30 device.

Table 1. Experimental data of performance parameters of pristine-polymer and composite-based OSCs.

\begin{tabular}{ccccc}
\hline \multirow{2}{*}{ Device } & \multicolumn{4}{c}{ Performance parameters } \\
\cline { 2 - 5 } & $V_{o c}(\mathrm{~V})$ & $J_{s c}\left(\mathrm{~mA} / \mathrm{cm}^{2}\right)$ & FF & $\eta(\%)$ \\
\hline P3HT & 0.89 & 4.1 & 0.52 & 1.89 \\
P3CT-3.0 & 0.87 & 5.05 & 0.54 & 2.35 \\
\hline
\end{tabular}




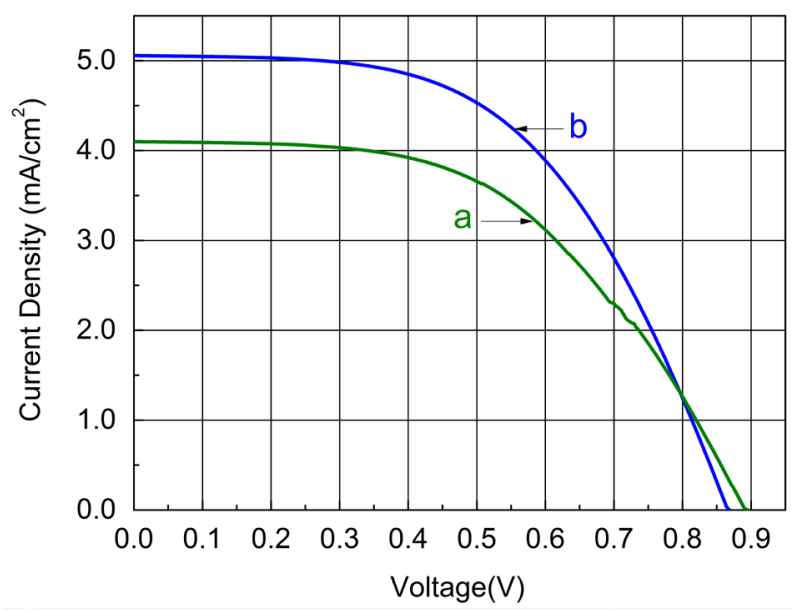

Figure 5. "a" is the J-V characteristic of a pristine P3HT-based device and "b" $-\mathrm{J}-\mathrm{V}$ of the P3CT-30 based device.

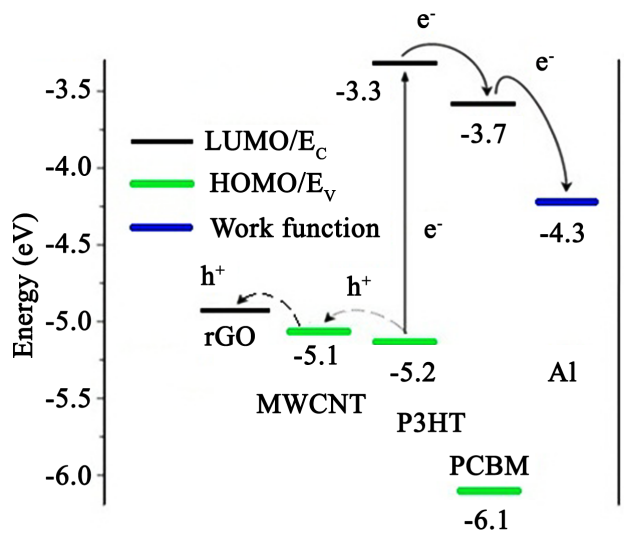

Figure 6. Scheme of the energy levels of single components of the composite solar cell embedded with MWCNTs. The dashed and solid arrows indicate hole and electron movement directions, respectively.

From Figure 6 one can see that due to a high value (namely $5.1 \mathrm{eV}$ ) of the work function, MWCNTs favor holes injection from the polymer blend to the nanotubes. This results in a fast extraction of them to the electrode. Indeed, as reported in [20], acting as the exciton dissociation sites, MWCNTs embedded in P3HT have contributed to a considerable increase in the power conversion efficiency of the composite device. Although the flexible GPP used for the anode in the device has a transmittance lower than that of the standard ITO-coated glass, the PCE of the composite OSC attained a value as large as $2.35 \%$ that is still small in comparison to the PCE of the inorganic solar cells. Taking advantage of the facile preparation of large-area OSCs, one can expect potential applications of the flexible TCE and MWCNTs-additive photoactive layer for solar power production.

\section{Conclusions}

MWCNTs were embedded with an optimum percentage of $3.0 \mathrm{wt} \%$ in conduct- 
ing polymer, $\mathrm{P} 3 \mathrm{HT}$, for the photoactive layer in the flexible solar cells $\mathrm{PET} / \mathrm{rGO}-\mathrm{P} 3 \mathrm{HT} / \mathrm{P} 3 \mathrm{CT} / \mathrm{PCBM} / \mathrm{LiF}-\mathrm{Al}$. Characterization of the UV-Vis absorption spectra of the photoactive films as well as the current-voltage curves of the devices showed that the composite OSCs exhibited a much larger photoelectrical conversion efficiency in comparison with the polymeric solar cell. Under illumination of light with a power density of $100 \mathrm{~mW} / \mathrm{cm}^{2}$, the following parameters of the cells were obtained: $V_{o c}=0.87 \mathrm{~V}, J_{s c}=5.05 \mathrm{~mA} / \mathrm{cm}^{2}, \mathrm{FF}=0.54, \mathrm{PCE}=$ $2.35 \%$.

The obtained results suggest further useful applications of the flexible solar cells for effective solar power conversion, in terms of rolled large-area photovoltage panels.

\section{Acknowledgements}

We thank Dr. Bui Hung Thang (Institute of Materials Science, VAST) for supplying us with pure MWCNTs and rGO materials. The authors (from ARGD) express sincerely thanks to VNU-University of Engineering and Technology (VNU-UET) for the financial support under project number CN20.05.

\section{Conflicts of Interest}

The authors declare no conflicts of interest regarding the publication of this paper.

\section{References}

[1] Zhang, M., Höfle, S., Czolk, J., Mertens, A. and Colsmann, A. (2015) All-Solution Processed Transparent Organic Light Emitting Diodes. Nanoscale, 7, 20009-20014. https://doi.org/10.1039/C5NR05820A

[2] Luo, D., Chen, Q.B., Liu, B. and Qiu, Y. (2019) Emergence of Flexible White Organic Light-Emitting Diodes. Polymers, 11, 384. https://doi.org/10.3390/polym11020384

[3] Li, G., Zhu, R. and Yang, Y. (2012) Polymer Solar Cells. Nature Photonics, 6, 153-161.

[4] Gao, Y.Y., Wang, Z., Yue, G.T., Yu, X., Liu, X.S., Yang, G., Tan, F.R., Wei, Z.X. and Zhang, W.F. (2019) Efficient Polymer Solar Cells with High Fill Factor Enabled by a Furo[3,4-c]Pyrrole-4,6-Dione-Based Copolymer. Solar RRL, 3, Article ID: 1900012. https://doi.org/10.1002/solr.201900012

[5] Zhang, Z.J., Miao, J.H., Ding, Z.C., Kan, B., Lin, B.J., Wan, X.J., Ma, W., Chen, Y.S., Long, X.J., Dou, C.D., Zhang, J.D., Liu J. and Wang, L.X. (2019) Efficient and Thermally Stable Organic Solar Cells Based on Small Molecule Donor and Polymer Acceptor. Nature Communications, 10, Article No. 3271. https://doi.org/10.1038/s41467-019-10984-6

[6] Ren, S., Chang, L.Y., Lim, S.K., Zhao, J., Smith, M., Zhao, N., Bulovic, V., Bawendi, M. and Gradecak, S. (2011) Inorganic-Organic Hybrid Solar Cell: Bridging Quantum Dots to Conjugate Polymer Nanowire. Nano Letters, 11, 3998-4002. https://doi.org/10.1021/nl202435t

[7] Gelinck, G.H., Warman, J. and Staring, E.G.J. (1996) Polaron Pair Formation, Migration, and Decay on Photoexcited Poly(Phenylenevinylene) Chains. Journal of Physical Chemistry, 100, 5485-5491. https://doi.org/10.1021/jp9532071 
[8] Hummelen, J.C., Knight, B.W., Lepec, F. and Wudl, F. (1995) Preparation and Characterization of Fulleroid and Methanofullerene Derivatives. Journal of Organic Chemistry, 60, 532-538. https://doi.org/10.1021/jo00108a012

[9] Thomas, S., Joseph, K., Malhotra, S.K., Goda, K. and Sreekala, M.S. (2013) Polymer Composites, Nanocomposites. John Wiley \& Sons, Hoboken, $450 \mathrm{p}$. https://doi.org/10.1002/9783527674220

[10] Liu, R. (2014) Hybrid Organic/Inorganic Nanocomposites for Photovoltaic Cells. Materials, 7, 2747-2771. https://doi.org/10.3390/ma7042747

[11] Thao, T.T., Trung, T.Q., Truong, V.-V. and Dinh, N.N. (2015) Enhancement of Power Efficiency and Stability of P3HT-based Organic Solar Cells under Elevated Operating-Temperatures by Using a Nanocomposite Photoactive Layer. Journal of Nanomaterials, 2015, Article ID: 463565. https://doi.org/10.1155/2015/463565

[12] Cai, M., Tiong, V.T., Hreid, T., Bell, J. and Wang, H. (2015) Efficient Hole Transport Material Composite Based on Poly(3-Hexylthiophene) and Bamboo-Structure Carbon Nanotubes for High Performance Perovskite Solar Cells. Journal of Materials Chemistry $A, 3,2784-2793$. https://doi.org/10.1039/C4TA04997G

[13] Mombrú, D., Romero, M., Faccio, R. and Mombrú, A.W. (2018) Raman Microscopy Insights on the Out-of-Plane Electrical Transport of Carbon Nanotube-Doped PEDOT: PSS Electrodes for Solar Cell Applications. Journal of Physical Chemistry $B, 122$, 2694-2701. https://doi.org/10.1021/acs.jpcb.8b00317

[14] Kuila, B.K., Park, K. and Dai, L. (2010) Soluble P3HT-Grafted Carbon Nanotubes: Synthesis and Photovoltaic Application. Macromolecules, 43, 6699-6705.

https://doi.org/10.1021/ma100917p

[15] Jun, G.H., Jin, S.H., Lee, B., Kim, B.H., Chae, W.-S., Hong, S.H. and Jeon, S. (2013) Enhanced Conduction and Charge-Selectivity by N-Doped Grapheneflakes in the Active Layer of Bulk-Heterojunction Organic Solar Cells. Energy Environ. Sciences, 6, 3000-3006. https://doi.org/10.1039/c3ee40963e

[16] Long, L.M., Long, D.D., Nam, N.P.H., Tinh, N.T., Chizhik, S.A. and Dinh, N.N. (2018) Preparation and Characterization of Reduced Graphene-P3HT Composite Thin Films for Use as Transparent Conducting Electrodes, Materials Sciences and Applications, 9, 464-472. https://doi.org/10.4236/msa.2018.95032

[17] Thipperudrappa, J., Biradar, D.S. and Hanagodimath, S.M. (2007) Simultaneous Presence of Static and Dynamic Component in the Fluorescence Quenching of Bis-MSB by CCl4 and Aniline. Journal of Luminescence, 124, 45-50. https://doi.org/10.1016/j.jlumin.2006.02.001

[18] Chipara, M. and Chipara, M.D. (2008) Uv-Vis Investigations on Ion Beam Irradiated Polycarbonate. E-Polymers, Article No. 145.

[19] Berson, S., Bettignies, R., Bailly, S., Guillerez, S. and Jousselme, B. (2007) Elaboration of P3HT/CNT/PCBM Composites for Organic Photovoltaic Cells. Advanced Functional Materials, 17, 3363-3370. https://doi.org/10.1002/adfm.200700438

[20] Pradhan, B., Batabyal, S.K. and Pai. A.J. (2006) Functionalized Carbon Nanotubes in Donor/Acceptor-Type Photovoltaic Devices. Applied Physics Letters, 88, Article ID: 093106. https://doi.org/10.1063/1.2179372 